\title{
The Effect of Coaching Leadership and Subordinate Psychological Capital on the Employee Voice Behavior
}

\author{
Chuqin Yuan, Yanfei Wang \\ School of Business Administration, South China University of Technology, Guangzhou, China
}

Email address:

bmyuancq@mail.scut.edu.cn (Chuqin Yuan),wangyanfeiscut@126.com (Yanfei Wang)

To cite this article:

Chuqin Yuan, Yanfei Wang. The Effect of Coaching Leadership and Subordinate Psychological Capital on the Employee Voice Behavior. Science Journal of Business and Management. Vol. 5, No. 2, 2017, pp. 59-63. doi: 10.11648/j.sjbm.20170502.13

Received: January 12, 2017; Accepted: March 2, 2017; Published: March 10, 2017

\begin{abstract}
Based on the theory of emotional contagion and similar attraction paradigm, this research explored the psychological mechanism of coaching leadership promoting employee voice behavior. The results showed that subordinate psychological capital mediated the relationship between coaching leadership and employee voice behavior. Moreover, supervisor employee dyadic tenure significantly moderated the positive relationships between coaching leadership and voice behavior. Research findings enrich theory and practice of coaching leadership.
\end{abstract}

Keywords: Coaching Leadership Behavior, Subordinate Psychological Capital, Voice Behavior, Supervisor Employee Dyadic Tenure, Emotional Contagion Theory, Similarity Attraction Paradigm

\section{Introduction}

With the rapid development of information technology, new business models are continually emerging. In order to cope with the challenges, organizations should obtain information from varied sources and come up with new ideas. Meanwhile, time and energy of managers are so limited that advices from employees are important for organizational innovation and development. However, employees do not dare to take the initiative to express their ideas because of the influence of Chinese traditional culture such as "face", "guanxi" and "humanity" [6]. Therefore, it is particularly important to build voice mechanism and encourage employees to open their mind.

Voice behavior refers to the extra-role behavior of an employee voluntarily offering constructive opinions to a superior in order to improve the efficiency of an organization [13]; [15]. Previous studies have shown that leadership is one of the key variables deciding whether employees are willing to express their ideas so as to improve organizational effectiveness [1]; [7]. Under the new management situation, as new management means and important way to develop and improve abilities of employees, positive effects of coaching leadership on employees and the organization are paid more and more attention [20]; [12]. Coaching leadership focuses on the improvement of employees' mental modes and the development of employees' intellectual potential, thereby achieving a win-win situation between employees and organizations via the establishment of a good leader-member interactive relationship [9]. Studies have shown that coaching leadership is an important antecedent for employee attitudes, in-role performance and extra-role performance [23]; [10]; [11]. Therefore, one of the most important objectives of this study is to explore the relationship between coaching leadership and employee voice behavior.

In addition, exploring the mediating mechanism and boundary conditions are significant if the coaching leadership is one of the most important driving factors for employee voice behavior. According to the theory of emotional contagion, the infection effect of leaders influencing subordinate behavior need through certain psychological mechanism to implement [8]. Leaders influence subordinates' psychological state through infecting employees' positive emotions, and then affecting employees' attitude and behavior [21]. Psychological capital, as an important concept of positive psychology theory, has the driving effect that improving employees' positive work attitude and behavior has been widely validation [4]; [19]. Therefore, coaching leadership influences indirectly voice behavior of subordinates through subordinates' psychological capital. Subordinate psychological capital plays an intermediary role between coaching leadership and employee voice behavior. 
Previous studies have found that there is a certain logic relationship among coaching leadership, subordinate psychological capital and employee voice behavior [22]; [23]; [17]; [11].

The discussion about supervisor employee dyadic tenure and its effect is profound [25]. From the perspective of theory analysis, the length of working together time of leader and subordinate can affect the relationships among employees, and then affect their work behavior [25]. According to similarity attraction paradigm (SAP) of interperson, with the longer working time, the two sides will be more similar and the more positive interactions will [5]; [18]. As a result, supervisor employee dyadic tenure is likely to become important environment variables that leadership influences the behavior of subordinates.

To sum up, based on emotional contagion theory and similarity attraction paradigm, this research will explore the following questions: first, how coaching leadership affect employee voice behavior, and whether subordinate psychological capital plays a mediating role between coaching leadership and employee voice behavior; second, whether supervisor employee dyadic tenure plays a moderating role between coaching leadership and employee voice behavior. Therefore, the following hypotheses are proposed:

Hypothesis 1 (H1): Coaching leadership is positively associated with employee voice behavior.

Hypothesis 2 (H2): Subordinate psychological capital mediates the relationship between coaching leadership and employee voice behavior.

Hypothesis 3 (H3): Supervisor employee dyadic tenure moderates the relationship between coaching leadership and employee voice behavior.

\section{Methodology}

\subsection{Participants and Procedure}

The participants of the study were managers and their direct subordinates employed by enterprises in South China. To avoid same source bias and common method variance, data were collected using the supervisor-subordinate pairing mode from a cross-period research. Data collection process is as follows: first, the participants are volunteered to participate in this survey from MBA class of SCUT, and they are asked to provide their email address and direct subordinates to us. Then our research team staff directly contact with them by sending and receiving the questionnaire via email. All variables were measured at different times using an interval of three months between each of the three tests: T1, T2 and T3. At T1, the supervisors completed the questionnaires on coaching leadership (CL). At T2 (three months later), the employees completed the questionnaires on supervisor employee dyadic tenure (SEDT) and subordinate psychological capital (SPC). At T3 (again, three months later), the supervisors completed the questionnaires on voice behavior (VB).
From the 135 supervisor and 420 employee questionnaires distributed, we received 106 supervisor forms (response rate of $78.5 \%$ ) and 368 employee forms (response rate of $87.6 \%$ ) in return. In the final sample, there were 343 dyads matched. Of the supervisors: $62.3 \%$ were men and $37.7 \%$ were women, aged between 24-58 years (average age of 36.9 years), and they reported an average period of tenure in the enterprise of 11.8 years. As to the subordinates: age distribution was between 21-53 years (average age of 27.4 years), and they reported an average work experience of 6.5 years.

\subsection{Measures}

All variables were measured using a 5-point Likert type scale ranging from 1 (strongly disagree) to 5 (strongly agree). All scales were chosen from those in previous literature, and because the coaching leadership and voice behavior scales were derived from an English version, we conducted a translation/back-translation procedure to avoid misunderstanding in our Chinese version.

Coaching leadership: Coaching Leadership was measured using the 12-item scale. It was developed and validated by Anderson (2013) [3]. Sample item is "I am very good at helping them (employees) all to express their own action plans". Cronbach's alpha was .757 . The confirmatory factor analysis results shown that the variable has high construct validity $\quad\left(\chi^{2} / \mathrm{df}=2.788, \quad \mathrm{RMSEA}=0.072, \quad \mathrm{GFI}=0.943\right.$, $\mathrm{CFI}=0.914, \mathrm{RMR}=0.034)$.

Subordinate psychological capital: Subordinate PsyCap was measured with a 24-item scale developed by Youssef and Luthans (2007) [26] to measure employees' self-efficacy, hope, optimism, and resilience. Sample item is "I feel confident in representing my work area in meetings with management". Cronbach's alphas was.847. The confirmatory factor analysis results shown that the variable has high construct validity $(\chi 2 / \mathrm{df}=1.986, \mathrm{RMSEA}=0.054, \mathrm{GFI}=0.900$, $\mathrm{CFI}=0.903, \mathrm{RMR}=0.035$ ).

Supervisor employee dyadic tenure: In the questionnaire survey, this was rated by the followers to answer tenure with their direct supervisor. Tenure with leader was divided into five groups (less than 1 year, 1-2 years, 2-3 years, 3-5 years, more than 5 years).

Voice behavior: This was rated by the supervisor using an 11-item scale developed by Liang and Farh (2008) [14] to measure employees' voice behavior. Sample item is "Raise suggestions to improve the unit's working procedure". Cronbach's alphas was.902. The confirmatory factor analysis results shown that the variable has high construct validity $\left(\chi^{2} / \mathrm{df}=2.661, \quad \mathrm{RMSEA}=0.070, \quad \mathrm{GFI}=0.949, \quad \mathrm{CFI}=0.966\right.$, $\mathrm{RMR}=0.034, \mathrm{IFI}=0.966)$.

Control variables: We included employee gender, age, education, organizational tenure and tenure with leader as the control variables that impact on employee voice behavior. Gender (male or female) was binary variable. Age was divided into six groups (younger than 25, 26-30, 31-35, 3640, 41-50 and older than 50), education level was divided into four groups: 1) high school and below, 2) college, 3) university, and 4) postgraduate. Organizational tenure was 
divided into five groups (less than 2 years, 2-4 years, 5-7 years, $8-10$ years, more than 10 years).

\section{Results}

\subsection{Confirmatory Factor Analysis}

Three variables were employed in our study: 1) coaching leadership, 2) follower psychological capital, 3) voice behavior. Table 1 presents the results of the confirmatory factor analysis that examined the distinctiveness of the study variables. We compared three factors model with single factor model and nine factors model. Three factors model fit the data well $(\chi 2 / \mathrm{df}=1.994, \mathrm{CFI}=.907, \mathrm{GFI}=.888, \mathrm{RMR}$ $=.044$, RMSEA=.054).

Table 1. The Results of Confirmatory Factor Analysis.

\begin{tabular}{lllllll}
\hline Variables & $\chi^{2}$ & $\boldsymbol{D f}$ & $\chi^{2} / \boldsymbol{d f}$ & $\boldsymbol{R M S E} \boldsymbol{G}$ & $\boldsymbol{G F I}$ & $\boldsymbol{R} \boldsymbol{M} \boldsymbol{R}$ \\
\hline CL, FPC, VB & 628.110 & 315 & 1.994 & 0.054 & 0.888 & 0.907 \\
CL, FPC+VB & 1474.241 & 320 & 4.607 & 0.103 & 0.734 & 0.636 \\
CL+FPC+VB & 1542.025 & 322 & 4.789 & 0.105 & 0.718 & 0.619 \\
\hline
\end{tabular}

Note. CL: Coaching Leadership; SPC: Subordinate psychological capital; VB: Voice Behavior.

\subsection{Descriptive Statistics}

Means, standard deviations, reliabilities, and correlations for all variables are presented in Table 2. The results of this study in Table 2 provide a preliminary support for related hypothesis testing.

Table 2. Mean, Standard Deviation and Correlations of Main Variables.

\begin{tabular}{|c|c|c|c|c|c|c|}
\hline Variables & $\mathbf{M}$ & SD & 1 & 2 & 3 & 4 \\
\hline 1. Supervisor employee dyadic tenure (SEDT) & 2.95 & 1.46 & - & - & & \\
\hline 2. Coaching leadership (CL) & 3.81 & .319 & $.104^{*}$ & $(0.757)$ & & \\
\hline 4. Voice behavior $(\mathrm{VB})$ & 3.64 & .646 & $.103^{*}$ & $.440^{* *}$ & $.165^{* *}$ & $(0.902)$ \\
\hline
\end{tabular}

Note. $\mathrm{N}=343$. Cronbach's alpha reliabilities are in parentheses on the diagonal. $* * \mathrm{p}<0.01, * \mathrm{p}<0.05$.

\subsection{Hypothesis Testing}

This study uses the way of multiple regression analysis to test the hypotheses. H1 puts forth that coaching leadership is positively related to voice behavior. Our results shown in Table 3 supported this view $(\beta=.245, \mathrm{p}<.01)$. $\mathrm{H} 2$, which states that FPC mediates the relationship between coaching leadership and voice behavior, received support as well $\left(\beta_{1}=.245, \mathrm{p}_{1}<.01 ; \beta_{2}=.067, \mathrm{n} . \mathrm{s}\right.$.). That is, SPC played a full mediating role between coaching leadership and voice behavior. The results shown in Table 3 reveal the interaction term between CL and SEDT was significant $(\beta=.105, \mathrm{p}<.05)$. Thus H3 was also supported.

Table 3. Results of Multiple Regression Analysis.

\begin{tabular}{|c|c|c|c|c|c|}
\hline \multirow{2}{*}{ Variables } & \multicolumn{2}{|c|}{ FPC } & \multicolumn{3}{|c|}{ VB } \\
\hline & M1 & M2 & M3 & M4 & M5 \\
\hline 1. Gender & -.061 & -.057 & -.056 & -.026 & -.007 \\
\hline 2. Age & $-.060^{*}$ & -.053 & -.055 & $-.069 *$ & -.010 \\
\hline 3. Education & .047 & .045 & .045 & .081 & .069 \\
\hline 4. Tenure & $.053^{*}$ & .043 & .039 & .038 & -.104 \\
\hline 5. Coaching leadership (CL) & & $.279 * *$ & $.245^{* *}$ & .067 & $.205 * *$ \\
\hline 6. Subordinate psychological capital (SPC) & & & & $.315^{* *}$ & \\
\hline 7. Supervisor employee dyadic tenure (SEDT) & & & & & $.167^{*}$ \\
\hline 8. CL*SEDT & & & & & $.105^{*}$ \\
\hline$\Delta \mathrm{R}^{2}$ & $0.017 *$ & $0.191 * * *$ & $0.193 * * *$ & $0.198 * * *$ & $0.224 * * *$ \\
\hline
\end{tabular}

Note. ${ }^{* * *}: p<.001 ;{ }^{* *}: p<.01 ;{ }^{*}: p<.05$.

Following Aiken and West (1991) [2], we plotted the interaction picture shown in Figure 1. We drew the picture at 1SD above and 1SD below the mean of supervisor employee dyadic tenure (SEDT). The result showed that when individuals had longer time working with their superiors, coaching leadership was more positively associated with voice behavior. Therefore, H3 was confirmed again. 


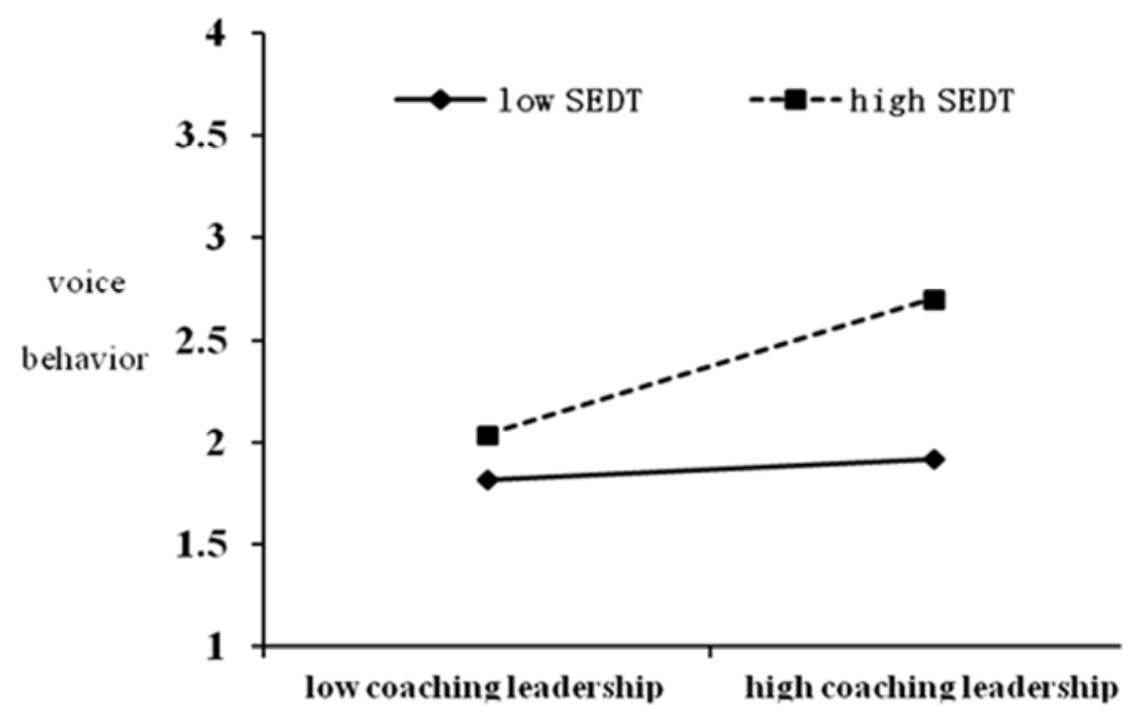

Figure 1. The interaction effect of SEDT and CL on VB.

\section{Discussion}

Main contribution of this study is that, under management situation in China, we tested the influence and mechanism of action between coaching leadership and employee voice behavior through empirical research. This study can enrich theory and related knowledge of coaching leadership.

From the perspective of emotional contagion, this study analyzes influencing process of coaching leadership on employee voice behavior through the psychological mechanism of superior and subordinate, and provides a new theoretical perspective to explain the relationship between leadership and voice behavior. The reason why coaching leadership can facilitate employee voice behavior is that coaching leadership can affect or shape employees' related psychological state and cognition, which will have effect on employee voice behavior [17]. In addition, this study combined with similar attraction paradigm, from the perspective of working situation characteristic, verifies supervisor employee dyadic tenure playing an important role in the process of coaching leadership effecting on voice behavior. Thereby boundary conditions that coaching leadership influencing on voice behavior were determined under the situation in China. The conclusions coincide with the specific social culture of China [16].

Our study can also provide management enlightenment to promote employee voice behavior. The verdicts show that coaching leadership has a significant effect on employee voice behavior. So leaders should create a harmonious atmosphere in the work, and give the subordinate perceived trust, weakening concept of "Shang Zun Xia Bei" attached to Confucian culture in China, and then encouraging subordinate throw away concerns to express their ideas. Supervisor employee dyadic tenure has significant moderating role between coaching leadership and voice behavior. This result prompts leaders to fully understand the qualities of the applicants whether match the organizational development when recruiting new employees to reduce staff turnover frequently. On the other hand, old employees should be given incentives for attracting them to remain in the tissues.

There are still some limitations and deficiencies of this study. First, the samples of this study are mostly concentrated in southern China, and the results remain to be further discussed because cultural differences of different regions in China may affect the research conclusion. Future research can expand the scope and size of sample to enhance persuasion of research conclusion. Second, this study focuses on the single matching relations between supervisor and subordinate, but ignoring integration effect of leaders at all levels in the organization. Trickle-down theory provides a new train of thoughts to compensate for the shortcomings mentioned above. This theory deems that leadership effectiveness trickles down gradually along the vertical organizational hierarchy, ultimately affecting the behavior of grass-roots staff. Future research can explore the inner driving mechanism and boundary conditions of employee voice behavior from the perspective of senior leaders impacting junior managers.

\section{Conclusion}

This study, based on the theory of emotional contagion and similar attraction paradigm, examined the psychological mechanism and boundary condition that coaching leadership improving employee voice behavior. We verified subordinate PsyCap constitute a key mediating mechanism between coaching leadership and employee voice behavior, and supervisor employee dyadic tenure moderated the relationship between coaching leadership and voice behavior.

\section{Acknowledgements}

This study was supported by grants from the Natural Science Foundation Program of Guangdong Province 
(408277493017), the General Youth Foundation Program of the Ministry of Education of Humanities and Social Science (15YJC630197), and the Soft Science Program of Guangdong Province (2014A070703021).

\section{References}

[1] Agustiningsih, H. N., Thoyib, A., H, D., \& Noermijati, N. 2016. The Effect of Remuneration, Job Satisfaction and OCB on the Employee Performance. Science Journal of Business and Management, 4(6), 218-228.

[2] Aiken, L. S, \& West, S. G.1991. Multiple regression: Testing and interpreting interactions. Newbury Park, CA: Sage.

[3] Anderson, V. 2013. A Trojan horse? The implications of managerial coaching for leadership theory. Human Resource Development International, 16(3), 251-266.

[4] Avey, J. B., Reichard, R. J., Luthans, F., \& Mhatre, K. H. 2011 Meta-analysis of the impact of positive psychological capital on employee attitudes, behaviors, and performance. Human Resource Development Quarterly, 22(2), 127-152.

[5] Byrne, D. 1997. An overview (and underview) of research and theory within the attraction paradigm. Journal of Personality \& Social Psychology, 14(3), 417-431.

[6] Chen, X. P., \& Chen, C. C. 2004. On the intricacies of the Chinese guanxi: A process model of guanxi development. Asia Pacific Journal of Management, 21(3), 305-324.

[7] Detert, J. R., \& Burris, E. R. 2007. Leadership behavior and employee voice: Is the door really open?. Academy of Management Journal, 50(4), 869-884.

[8] Falkenberg, I., Bartels, M., \& Wild, B. 2008. Keep smiling Facial reactions to emotional stimuli and their relationship to emotional contagion in patients with schizophrenia. European Archives of Psychiatry and Clinical Neuroscience, 258, 245253.

[9] Hagen, M., \& Gavrilova Aguilar, M. 2012. The impact of managerial coaching on learning outcomes within the team context: An analysis. Human Resource Development Quarterly, 23(3), 363-388.

[10] Huang, J. T., \& Hsieh, H. H. 2015. Supervisors as good coaches: influences of coaching on employees' in-role behaviors and proactive career behaviors. The International Journal of Human Resource Management, 26(1), 42-58.

[11] Kim, S., \& Kuo, M. H. 2015. Examining the Relationships Among Coaching, Trustworthiness, and Role Behaviors A Social Exchange Perspective. The Journal of Applied Behavioral Science, 51(2), 152-176.

[12] Kim, S. 2014. Assessing the influence of managerial coaching on employee outcomes. Human Resource Development Quarterly, 25(1), 59-85.
[13] LePine, J. A., \& Van Dyne, L. 1998. Predicting voice behavior in work groups. Journal of applied psychology, 83(6), 853.

[14] Liang, J., \& Farh, J. L. 2008. Promotive and prohibitive voice behavior in organizations: A two-wave longitudinal examination. In Third international association of Chinese management research conference, Guangzhou, China.

[15] Liu, W., Song, Z., Li, X., \& Liao, Z. 2015. Why and when leader's affective states influence employee upward voice. Academy of Management Journal, amj-2013.

[16] Li, Y., \& Sun, J. M. 2015. Traditional Chinese leadership and employee voice behavior: A cross-level examination. The Leadership Quarterly, 26(2), 172-189.

[17] Pousa, C., \& Mathieu, A. 2015. Is managerial coaching a source of competitive advantage? Promoting employee self-regulation through coaching. Coaching: An International Journal of Theory, Research and Practice, 8(1), 20-35.

[18] Sparrowe, R. T., Liden, R. C., Wayne, S. J., \& Kraimer, M. L. 2001. Social networks and the performance of individuals and groups. Academy of management journal, 44(2), 316-325.

[19] Story, J. S., Youssef, C. M., Luthans, F., Barbuto, J. E., \& Bovaird, J. 2013. Contagion effect of global leaders' positive psychological capital on followers: does distance and quality of relationship matter?. The International Journal of Human Resource Management, 24(13), 2534-2553.

[20] Theeboom, T., Beersma, B., \& van Vianen, A. E. 2014. Does coaching work? A meta-analysis on the effects of coaching on individual level outcomes in an organizational context. The Journal of Positive Psychology, 9(1), 1-18.

[21] Vijayalakshmi, V., \& Bhattacharyya, S. 2012. Emotional contagion and its relevance to individual behavior and organizational processes: A position paper. Journal of Business and Psychology, 27(3), 363-374.

[22] Walumbwa, F. O., Morrison, E. W., \& Christensen, A. L. 2012 Ethical leadership and group in-role performance: The mediating roles of group conscientiousness and group voice. The Leadership Quarterly, 23(5), 953-964.

[23] Wang, D., Gan, C., Wu, C., \& Wang, D. 2015. Ethical leadership and employee voice: Employee self-efficacy and self-impact as mediators. Psychological reports, 116(3), 751-767.

[24] Wang, Y. L. 2013. R\&D employees' innovative behaviors in Taiwan: HRM and managerial coaching as moderators. Asia Pacific Journal of Human Resources, 51(4), 491-515.

[25] Wieseke, J., Ahearne, M., Lam, S. K., \& Dick, R. V. 2009. The role of leaders in internal marketing. Journal of Marketing, 73(2), 123-145.

[26] Youssef, C. M., \& Luthans, F. 2007. Positive organizational behavior in the workplace the impact of hope, optimism, and resilience. Journal of management, 33(5), 774-800. 